\title{
Teknokultura
}

ISSNe: 1549-2230

http://dx.doi.org/10.5209/TEKN.58444

\section{Una de las crisis del periodismo pasa por esa desconexión con el lector, con la ciudadanía. Entrevista con Alejandro Rost}

\author{
Patrícia Specht ${ }^{1}$
}

Recibido: 19 de diciembre de 2017 / Aceptado: 28 de marzo de 2018 Open peer reviews

Resumen. En esta entrevista, Alejandro Rost, profesor de la Universidad Nacional de Comahue, en Argentina, reflexiona sobre las actuales relaciones de interactividad establecidas entre los medios de comunicación y sus públicos, afirmando que con la ampliación de la visibilidad del usuario, aumenta la necesidad de que estos vehículos de comunicación encuentren estrategias y mecanismos para administrar de manera más productiva la contribución del lector. Es decir, aunque hubo un incremento en la participación, los vehículos de comunicación continúan administrando mal el material aportado por el lector. Rost ha concedido esta entrevista a Patricia Specht, estudiante de postgrado de la Pontificia Universidad Católica de Rio Grande do Sul (PUCRS), durante el Congreso Internacional de Ciberperiodismo de Campo Grande (MT), en Brasil, en septiembre de 2017, ocasión en que él fue el orador.

Palabras clave: Alejandro Rost; interactividad; periodismo digital.

\section{[en] One of main crisis of journalism is a disconnection with readers and citizenship. Interview with Alejandro Rost}

\begin{abstract}
In this interview, professor Alejandro Rost, from the National University of Comahue, Argentina, reflects about the contemporary interactive relationship established between media and their public, and affirms that, with the extension of user visibility, there is an increase in the need for communication vehicles to find strategies and mechanisms to better manage the reader's contributions. The participation of readers has increased, but the vehicles continue to mismanage the material originating from them. Rost gave this interview to Patrícia Specht, a postgraduate student at the Pontifícia Universidade Católica of Rio Grande do Sul (PUCRS), during the 8th International Congress of Cyberjournalism in Campo Grande (MT), in Brazil, in September 2017, where Rost was an orator.
\end{abstract}

Keywords: Alejandro Rost; digital journalism; interactivity.

Sumario. 1. Introducción. 2. Entrevista. 3. Referencias

Cómo citar: Specht, P. (2018). Una de las crisis del periodismo pasa por esa desconexión con el lector, con la ciudadanía. Entrevista con Alejandro Rost, en Teknokultura 15(2), 357-362.

1 Pontificia Universidad Católica de Rio Grande do Sul (Brasil)

e-mail: patipspecht@gmail.com 


\section{Introducción}

Los conceptos de interactividad comunicativa y selectiva desarrollados por Alejandro Rost, doctor en Periodismo y Comunicación por la Universidad Autónoma de Barcelona, y profesor e investigador de la Universidad Nacional de Comahue, en Argentina, tienen más de 10 años de antigüedad. Su tesis fue publicada en 2006 y su investigación realizada entre 2001 y 2004, tomando como referencia cuatro webs de noticas, dos españolas y dos argentinas, las más visitadas y de mayor influencia en ambos países.

En la interactividad selectiva propuesta por Rost, el público controla el proceso de recepción de los contenidos a partir de elementos de selección como la hipertextualidad, el menú, las palabras clave, la personalización, entre otros. La interactividad comunicativa, a su vez, contempla más que opciones preestablecidas, representa las posibilidades de comunicación y expresión que el usuario tiene ante los contenidos del medio, permitiendo mecanismos de diálogo y discusión. En la práctica, este tipo de interactividad se expresa por medio de comentarios abajo de las noticias, perfiles en redes sociales abiertas a la participación de usuarios, blogs de ciudadanos, encuestas, foros, publicación de emails de periodistas, ranking de noticias, chats, envío de noticias/ fotografías/vídeos, etc.

En esta entrevista, realizada durante el $8^{\circ}$ Congreso Internacional de Ciberperiodismo, en Campo Grande (MS), Brasil, la interactividad es repensada bajo la luz del desarrollo y la apropiación de los instrumentos tecnológicos y de los sitios de redes sociales, que revolucionan el ambiente mediático y alteran las relaciones entre los vehículos de comunicación y sus audiencias.

\section{Entrevista}

Entrevistadora: La conclusión de sus estudios para la tesis (Rost, 2006), publicada en 2006, no fue muy emocionante, o sea, los vehículos de comunicación seguían lejos de explotar las posibilidades interactivas del medio digital, especialmente la interactividad comunicativa. En las pocas veces que aprovechaban el material del público, casi siempre usaban la contribución en espacios discretos, aislados del noticiero o entonces, muy escondidos, o sea, el lector/colaborador no se presentaba visible y su participación no transcendía. Su análisis detectó tres estrategias: los vehículos de comunicación buscan opinión del lector sobre temas de la actualidad (creación de contenidos), incentivan relaciones y encuentros entre los propios lectores (basada en conectividad) y además ponen de acuerdo ambas las estrategias. ¿Qué ha cambiado en este período?

Rost: Ha cambiado bastante. A partir del 2006, que fue el año que publiqué la tesis, las opciones de interactividad se han incrementado. Hay mayor visibilidad del usuario, claramente. En esa época, en 2006, recién estaban naciendo las redes sociales y creo que ese fue un factor fundamental. Fue en 2009, más o menos, que se consolidaron las redes sociales como posibilidad para el periodismo, cuando empezaron a utilizárselas con mayor frecuencia. Las redes sociales abrieron una instancia tanto a nivel de interactividad selectiva como, sobre todo, a nivel de interactividad comunicativa, en el sentido que, le dan, le ofrecen una plataforma más sencilla al usuario para publicar, para expresarse y para comunicarse con otros usuarios.

Así que, se han ampliado, digamos, las posibilidades de participación de los usuarios, se ha ampliado la visibilidad. En aquel momento, además, el lector estaba en 
un compartimento diferente de la noticia, eran espacios separados y no vinculados. Había un espacio para Foros, donde el lector podía participar, pero no se cruzaba con la noticia, o sea, periodistas y usuarios estaban en espacios distintos. Esto fue cambiando justamente a partir de estos años, primero con los comentarios debajo de cada noticia. El usuario empezó así a participar en el mismo entorno, con el periodista.

Luego, en las redes sociales, los usuarios empiezan a compartir noticias, a veces en espacios privados, o sea, en el propio muro, en su propio Facebook y se da una interacción con la noticia que antes no existía.

En ese sentido, creo que hay una mayor participación de los usuarios. Pero, bueno, sigue estando lejos del ideal de participación que uno podría esperar de un medio. No hay esa vinculación entre periodistas y usuarios que uno podría esperar, que uno quisiera, con el objetivo de enriquecer el debate público. Que haya mayor participación, mayor cantidad de voces, mayor pluralidad.

Esa participación, digamos, sigue siendo una participación muy errática, muy de escribir en una pared, digamos, sin que nadie responda, rara vez un periodista responde a esos usuarios. Y rara vez, reutiliza esa información que le aporta el usuario. Entonces, por ejemplo, los espacios para los comentarios, suelen ser espacios donde abundan los insultos, o algunas intervenciones que no tienen valor informativo, valor periodístico. En la medida que no hay una conexión ahí, no hay un diálogo entre periodistas y usuarios, no hay una buena interactividad. Sigue faltando, digamos, una producción que aproveche esa participación de los usuarios, que aproveche esos contenidos de los usuarios, que los reutilice, que desarrolle una enriquecedora interactividad comunicativa.

Entrevistadora: ¿Qué más pesa, la crisis de la industria del periodismo, que le saca y precariza a las redacciones, o el hecho cultural, ya que existe una clara resistencia de apertura?

Rost: Pesa el factor cultural de esa vinculación histórica del periodista, en una relación de poder con los usuarios, con los lectores. Y cuesta ponerse en el mismo nivel que los lectores. Y pesan también las rutinas de trabajo que imperan en las redacciones hoy, que es una rutina que está muy absorbida por la noticia de último momento, por publicar rápido. Esa rutina de producción no integra lo que es la participación de los usuarios, no está incluida en las tareas previstas para el periodista. En todo caso, hay una empresa, muchas veces tercereada, que se dedica a controlar esos comentarios para sacar lo que puede ser difamatorio, lo que puede ser un insulto, pero no más que eso. No está incluida dentro de las rutinas de producción del periodista esa interactividad con los usuarios.

Entrevistadora: Y a Usted, ¿le parece que esa interactividad puede mejorar el producto final, o sea, la noticia?

Rost: Seguro que sí. Hay muchos casos donde los usuarios intervienen y resulta que aportan más información de lo que aporta la propia noticia. $\mathrm{O}$ bien porque fueron testigos de lo que se sucedió, o porque tengan alguna información que el periodista desconozca. Puede que son entendidos en la materia, entendidos en el tema. Muchas veces, esos usuarios tienen informaciones para aportar y la aportan. Lo que pasa es que, el medio no las toma, quedan ahí, sin ser utilizadas, o sea, sin ser valoradas por el medio. Eso pasa muchas veces. Creo, además, que hay un problema de escala también. Los medios grandes, sobre todo, se ven sobrecargados por la cantidad de comentarios. O sea, es una participación que excede muchas veces las posibilidades de administración del medio. 
Sin duda hay que buscar formas de administrar todo eso. Quizás aprender de otros sitios, por ejemplo, de ventas, como Mercado Libre, que se dedican a interactuar y a utilizar el valor del usuario, digamos, a utilizar lo que pueden aportar los usuarios para mejorar esa interactividad. En cambio, por otro lado, los medios chicos, por ahí, tienen una escala de administración más factible, más posible de administrar. Igual es raro que lo hagan, lamentablemente. Pero creo que en el medio que no tiene tantos usuarios, esa posibilidad de interacción es más cercana.

Entrevistadora: Y siguiendo a su raciocinio, con esa multiplicidad de voces siendo escuchadas, viniendo por el usuario, mejorando el producto final, ¿podría ese producto final colaborar para, tal vez, recuperar la credibilidad de la actividad?

Rost: ¡Sin duda! Además, lo que mejora es, sobre todo, la relación con el lector. O sea, si el lector, el usuario ve que el medio lo escucha, lo atiende, y toma de su participación, toma contenidos de su participación, seguramente que esa relación, ese vínculo se estrecha, es mucho más profundo. Existe un mayor compromiso, fidelización, todo lo que se espera.

Entrevistadora: ¿Hay potencial del público en la producción de noticias? ¿Serían más fuentes en más lugares, en el escrutinio o como pauta? ¿En qué parte del proceso habría más potencial?

Rost: ¡En todos los aspectos! Es interesante ver en qué momento participa, si participa justamente en la última etapa, en la distribución o puede participar también en la parte de producción, en el aporte de la generación de la noticia. Ya sea dando el puntapié inicial, anunciando que pasó tal cosa al periodista para que él pueda ampliar o, en todo caso, contrastar las fuentes o enriqueciendo la primera producción sobre el tema. Lo que decís vos, el otro día, de la posibilidad de consultar a lectores, a usuarios que viven en una determinada zona auxilien a producir información de aquel lugar específico. Eso obliga al periodista a realizar todo un trabajo de chequeo, de constatación importante porque a muchos de esos usuarios, a muchas de esas fuentes, seguramente, no las conoce. Pero es un trabajo que puede ser muy enriquecedor, muy interesante. Porque, evidentemente, el periodista no puede llegar a todos los lugares, ni los fotógrafos, ni el camarógrafo puede llegar a todos lugares. Entonces, el usuario puede hacer un aporte.

Por otro lado, creo que el trabajo del periodista en la calle es muy importante. Porque hoy, de hecho, en esas rutinas de las que hablábamos, las rutinas de periódicos, de diarios digitales, muchos periodistas se las pasan en la redacción y no salen a la calle y, realmente, no es lo mismo. Estar en la calle te muestra la panorámica más amplia, te muestra todo, si uno lo sabe buscar, obviamente. Pero es donde uno puede consultar a la gente cara a cara, ver cómo es la situación, te brinda un montón de información que por ahí en WhatsApp es mucho más limitada.

Entrevistadora: ¿Por qué las estrategias de interactividad comunicativa en general son basadas en herramientas e iniciativas que escuchan la audiencia después de la noticia ser publicada, como es el caso de los comentarios y de las encuestas sobre las noticias? ¿Por qué los medios no escuchan a la audiencia antes de producir la noticia? Incluso, si así fuera, ella cambiaría bastante. ¿Por qué entonces eso no se hace así?

Rost: Bueno, ahora con WhatsApp sucede eso, la audiencia puede ser escuchada antes de la producción de las noticias. Lo primero que vi en el diario de aquí ${ }^{2}$, en

En Campo Grande, Mato Grosso do Sul (Brasil), en septiembre de 2017, donde Rost participó, como ponente, del $8^{\circ}$ Congreso Internacional de Ciberperiodismo. 
el diario impreso, fue justamente un aviso de WhatsApp, y ese mismo aviso estaba en el diario Rio Negro $^{3}$, en la Patagonia Argentina, tanto en el sitio web como en el diario impreso, así de color verde, como es el logo de WhatsApp. Los dos diarios seguramente no tienen ninguna vinculación, o sea, no es coincidencia. Eso está muy usado, ya está muy diseminado, esa herramienta, que es una posibilidad de recibir información que hay que aprovechar. Pero, claro, el medio tiene que aprovecharla, utilizándola, no dejar sin respuestas al lector, por horas, sin darles un feedback. Hay que tener una interacción ahí, con determinada frecuencia, con determinada actividad, si no tampoco sirve.

No es cuestión de abrir instancias de participación y después no gestionarlas, o sea, si uno abre la instancia de participación está obligado a gestionar, está obligado a trabajarla. No dejarla ahí. Abrir los comentarios y dejar que la gente diga lo que quiera y ya está. No. Son opciones para trabajar.

Entrevistadora: El profesional de las redacciones, delante de la oferta exagerada de contenidos y del protagonismo asumido por la audiencia, necesita reinventarse, o sea, las rutinas profesionales son otras, así como el producto en circulación, mucho más work in progress. ¿Eso afecta el chequeo y la apuración de datos? ¿Qué nuevo perfil de periodista vamos necesitar para este nuevo tiempo?

Rost: Un profesional que integre la interactividad en su rutina de trabajo, un profesional que conozca cuales son las posibilidades de interacción que tiene con el usuario y que las utilice, que las gestione. Un profesional atento a esa participación y a ver cómo puede enriquecer su trabajo con ella. $\mathrm{O}$ sea, es un aspecto fundamental que enriquece, que fortalece el lazo del medio con sus lectores, un lazo que está muy débil. Una de las crisis del periodismo pasa por esa desconexión con el lector, con la ciudadanía.

Entrevistadora: Y en relación a los cursos de graduación en periodismo, ¿qué formación deberían ofrecer?

Rost: Implica todo un cambio cultural, que es un cambio cultural importante. Y habitualmente cuando se piensa en la interactividad se critica al usuario, se critica al lector, por los contenidos que aportan, que no son sustanciales, pero no se ve todo el proceso. Cómo podría eso realmente mejorarse, alimentarse y generar una mejor conexión con ese usuario. En todos los procesos, no solamente en la última parte, cuando ya está publicada la noticia, sino también que en el proceso de elaboración, que también puede ser muy enriquecedor.

Yo creo que más allá de las herramientas, de las posibilidades de interacción, y de esta vinculación con el usuario, sigue siendo prioritario apostar por un periodismo de mejor calidad. Si uno ve en los últimos años, creo que ha mejorado mucho el periodismo en internet. $\mathrm{O}$ sea, por un lado, ha mejorado lo multimedia en algunos casos: hay más videos, hay mayor producción de filmografía, trabajo de periodismo de datos. Falta muchísimo, pero hay un mayor uso de hipertexto, hay opciones de interactividad, hay opciones de participación. Sin embargo, también se publica mucha información de apuro, sin chequear, con una sola fuente consultada, que luego termina siendo una noticia falsa o totalmente sesgada.

Entrevistadora: Aunque las transformaciones que el periodismo sufre alcanzan casi todas las etapas de producción y transmisión, el modelo de negocio parece no acompañar esa transformación. ¿Por qué?

3 Provincia de Argentina donde vive el investigador. 
Rost: También eso es un cambio importante, de modelo, a nivel social. Hay una forma de negocio de los medios tradicionales que no termina de morir y otra forma, de otros modelos de negocio que no terminan tampoco de consolidarse. Hay distintas formas que van apareciendo. El muro, por ejemplo, el muro de pago, el pago por cantidad de noticias, los sitios abiertos y financiados solamente por la publicidad, los sitios patrocinados. Hay distintos modelos, pero cada uno buscando de acuerdo a su volumen de audiencia, de acuerdo a sus características, a ver cuál se adapta mejor a sus posibilidades. Entonces, hasta que eso se consolide, estamos justamente en un momento de transición, una transición incómoda, no estamos ni en un lugar ni en otro. Muchos periodistas, por ejemplo, siguen trabajando con la cabeza puesta en el medio tradicional, el periódico impreso. Solo que ahora ellos también necesitan producir para la versión digital y para el móvil, la versión móvil. La rutina de trabajo sigue centrada en el medio tradicional, que todavía ofrece la mayor cantidad de recursos. Si bien estos recursos están disminuyendo y otros recursos van surgiendo, aunque no en la misma proporción.

\section{Referencias}

Rost, A. (2006). La interactividad en el periódico digital. (Tesis doctoral), Facultat de Ciències de la Comunicació, Universitat Autònoma de Barcelona, Barcelona, España. Recuperado de: http://www.tdx.cat/bitstream/handle/10803/4189/ar1de1.pdf

Rost, A. (2010). La participación en el periodismo digital: Muchas preguntas y algunas posibles respuestas. En Irigaray, F. (Org.). Periodismo Digital en un paradigma de transición: $2^{\circ}$ Foro de Periodismo Digital de Rosario (pp. 96-109). Rosario: Fundación La Capital.

Rost, A. (2012). Modelos de uso y gestión de redes sociales en el Periodismo. IV Congreso Internacional de Ciberperiodismo y Web 2.0. España, Bilbao.

Rost, A. (2014). Interatividade: Definições, estudos e tendências. En Canavilhas, J. (Org.), Webjornalismo: 7 características que marcam a diferença. Covilhã: UBI, LabCom, Livros LabCom, 2014. Recuperado de: http://www.labcom-ifp.ubi.pt/ficheiros/20141204-201404_ webjornalismo_jcanavilhas.pdf 